\title{
Prediction of the oxygenation of human organs at varying blood oxygen carrying properties
}

\author{
Michele Samaja \\ Dipartimento di Scienze e Tecnologie Biomediche, Istituto Scientifico San Raffaele, Milan, Italy
}

(Accepted for publication 30 December 1987)

\begin{abstract}
The oxygenation of some human organs (brain, heart, kidneys, and legs) is correlated to the oxygen carrying characteristics of blood by predicting the $\mathrm{Pv}_{\mathrm{O}_{2}}$ vs $\dot{\mathrm{Q}}$ relationship at a given metabolic level of the organ. The effect of moderate shifts of the oxygen equilibrium curve $[\approx 2 \mathrm{Torr}(0.27 \mathrm{kPa})$, comparable to the shifts caused by non-massive transfusions of blood with altered 2,3-diphosphoglycerate (DPG) concentration] is evaluated in terms of the efficiency of organ oxygenation. The results indicate the following. (1) An increase of the $P_{50}$ from 27.9 to 30.0 Torr ( 3.71 to $3.99 \mathrm{kPa}$ ), that is the consequence of an increase of the $[\mathrm{DPG}] /[\mathrm{Hb}]$ ratio from 0.8 to $1.04 \mathrm{M} / \mathrm{M}$, is advantageous for all organs, because the normal metabolic level can be maintained with a considerable reduction of $\dot{Q}(\sim 10 \%)$. (2) This reduction is similar to that caused by an increase of $[\mathrm{Hb}]$ from 160 to $182 \mathrm{~g} / \mathrm{L}$, but without increasing the blood viscosity and the vascular resistance. (3) This advantage is different for the various organs, as a function of their blood supply and metabolic level characteristics. These features were also observed at any $\mathrm{Pa}_{\mathrm{O}_{2}}$ in the range 60-300 Torr $(7.98-39.9 \mathrm{kPa})$, and when simulating acidemia or alkalemia, as well as a $\mathrm{pH}$ gradient across the organ.
\end{abstract}

Blood; Blood flow; 2,3-DPG; Oxygen dissociation curve; Organ respiration

Organs are widely different in terms of oxygen requirements and blood supply; however, the oxygen carrying characteristics of the blood that perfuses them are the same throughout. Thus, a given alteration of the oxygen carrying characteristics of the blood is expected to cause different responses from the various organs. This prediction was experimentally observed in rats (Woodson and Auerbach, 1982): an acute decrease of the $\mathrm{P}_{50}$ from 37 to 16 Torr $(4.92$ to $2.13 \mathrm{kPa}$ ) caused $\mathrm{Q}$ to increase in the heart, the brain and the liver, and to remain constant in the kidneys, thus stressing the importance of the oxygenation of the organs rather than of the whole body. However, the unphysiological changes of the oxygen carrying characteristics of the blood, and the use of an animal model made it difficult to evaluate the effect of the physiological shifts of the blood oxygen equilibrium curve (OEC) on the oxygenation of human organs. This problem is relevant in blood transfusion, because several experimental and theoretical

Correspondence address: Dr. M. Samaja, Dipartimento di Scienze e Tecnologie Biomediche, Via Olgettina 60, 20132 Milano, Italy.

0034-5687/88/\$03.50 (c) 1988 Elsevier Science Publishers B.V. (Biomedical Division) 
evidences (see Valeri, 1976, for a review) have established that rejuvenated red cells with high 2,3-diphosphoglycerate (DPG) concentration are preferable to untreated red cells with low DPG, but this advantage has not yet been quantitatively expressed with respect to the organs.

This study was undertaken to predict the responses of various organs to small $(\approx 2$ Torr, $0.27 \mathrm{kPa}$ ) shifts of the OEC, that are typically produced by non-massive transfusions of blood with altered DPG content. An already described model (Samaja et al., 1986) correlates $\mathrm{Pv}_{\mathrm{O}_{2}}$ to the blood flow that is necessary to maintain a predetermined metabolic level in a specific organ. The aims of this study are to show the differences in the oxygenation of the various organs, to estimate the size of the advantage of transfusing blood with high DPG concentration, and to describe a useful model to assess the quality of transfusion blood in terms of the effectiveness of the oxygenation.

\section{Methods}

The computer program is described in detail elsewhere (Samaja et al., 1986). Briefly, the input variables are the oxygen uptake $\left(\dot{\mathrm{V}}_{\mathrm{O}_{2}}\right)$, the hemoglobin $(\mathrm{Hb})$ and DPG concentrations, the venous and arterial base excess $(\mathrm{BE})$, the respiratory exchange ratio (R), $\mathrm{Pa}_{\mathrm{O}_{2}}, \mathrm{~Pa}_{\mathrm{CO}_{2}}$, and arterial $\mathrm{pH}$. Plasma proteins concentration and temperature are constant $\left(70 \mathrm{~g} / \mathrm{L}\right.$ and $37^{\circ} \mathrm{C}$, respectively). The aim of the program is to calculate $\dot{Q}$ at a given $\mathrm{Pv}_{\mathrm{O}_{2}}$. The solution is found iteratively until all the components of the system are satisfied: (1) $\mathrm{O}_{2}$ and $\mathrm{CO}_{2}$ mass balance, using the Fick and Henderson-Hasselbalch equations; (2) venous and arterial $\mathrm{BE}$, that might be different if $\mathrm{H}^{+}$are uptaken or released in the blood stream across the organ; (3) venous and arterial OEC (Winslow et al., 1983); (4) the Bohr effect, and thus the $\mathrm{pH}$ gradient across the organ driven by the binding of $\mathrm{H}^{+}$to $\mathrm{Hb}$ during $\mathrm{O}_{2}$ unloading. The lowest is the calculated $\dot{\mathrm{Q}}$ at a given $\mathrm{Pv}_{\mathrm{O}_{2}}$, the most efficient is the peripheral oxygenation, because a lower blood flow is required to supply a given amount of oxygen at constant values for the other parameters, and thus a lower load is required for the circulation.

The blood parameters were selected from the available literature accordingly to the cases described in table 1 . Assume an adult male subject with blood volume $=5 \mathrm{~L}$, $[\mathrm{Hb}]=160 \mathrm{~g} / \mathrm{L}$, and $[\mathrm{DPG}] /[\mathrm{Hb}]=0.8 \mathrm{M} / \mathrm{M}$ as recipient of the transfusion. The volume of the transfused blood is $1 \mathrm{~L},[\mathrm{Hb}]=160 \mathrm{~g} / \mathrm{L}$, and $[\mathrm{DPG}] /[\mathrm{Hb}]=0,0.8$, $2 \mathrm{M} / \mathrm{M}$, for outdated, fresh, and rejuvenated red cells, respectively. The [DPG]/[Hb] ratio in the rejuvenated blood is inferred assuming that fresh red cells undergo a $60 \mathrm{~min}$ incubation with $50 \mathrm{mM}$ pyruvate, $50 \mathrm{mM}$ inosine, $100 \mathrm{mM}$ glucose, $50 \mathrm{mM}$ phosphate and $5 \mathrm{mM}$ adenine, $\mathrm{pH} 7.4$ at $37^{\circ} \mathrm{C}$, as reported elsewhere (Valeri, 1976), before the transfusion. The term 'exchange transfusion' implies that $[\mathrm{Hb}]$ remains ideally constant and [DPG] $] /[\mathrm{Hb}]$ only varies, while the term 'transfusion' implies that an equal volume of plasma is expelled, and thus both $[\mathrm{Hb}]$ and $[\mathrm{DPG}] /[\mathrm{Hb}]$ change. This helps to distinguish the separate and the combined effects of $[\mathrm{Hb}]$ and $[\mathrm{DPG}] /[\mathrm{Hb}]$ on the oxygenation of the organs. The arterial blood values are $\mathrm{P}_{\mathrm{O}_{2}}=95$ Torr $(12.63 \mathrm{kPa})$, 


\section{TABLE 1}

Description of the cases with respect to the oxygen carrying characteristics of the blood (XT $=$ exchange transfusion; $T=$ transfusion). Assume that the volume of transfused blood is $1 \mathrm{~L}([\mathrm{Hb}]=160 \mathrm{~g} / \mathrm{L})$, and the volume of blood in the recipient is $5 \mathrm{~L}$. The $\mathrm{P}_{50}$ values are calculated at $\mathrm{pH} 7.4, \mathrm{P}_{\mathrm{CO}_{2}}=40$ Torr $(5.32 \mathrm{kPa})$, and the corresponding [DPG]/[Hb].

\begin{tabular}{|c|c|c|c|c|c|}
\hline \multirow[t]{2}{*}{ Description } & \multicolumn{2}{|l|}{$\begin{array}{l}\text { In transfused } \\
\text { blood }\end{array}$} & \multicolumn{3}{|c|}{$\begin{array}{l}\text { In the recipient of } \\
\text { the transfusion }\end{array}$} \\
\hline & $\begin{array}{l}{[\mathrm{DPG}] /[\mathrm{Hb}]} \\
(\mathrm{M} / \mathrm{M})\end{array}$ & $\begin{array}{l}\mathbf{P}_{50} \\
\text { (Torr) }\end{array}$ & $\begin{array}{l}{[\mathrm{Hb}]} \\
(\mathrm{g} / \mathrm{L})\end{array}$ & $\begin{array}{l}{[\mathrm{DPG}] /[\mathrm{Hb}]} \\
(\mathrm{M} / \mathrm{M})\end{array}$ & $\begin{array}{l}\mathrm{P}_{50} \\
\text { (Torr) }\end{array}$ \\
\hline (A) Control & - & - & 160 & 0.8 & 27.9 \\
\hline (B) XT outdated blood & 0.0 & 14.7 & 160 & 0.64 & 26.2 \\
\hline (C) XT rejuvenated blood & 2.0 & 37.4 & 160 & 1.04 & 30.0 \\
\hline (D) $\mathrm{T}$ fresh blood & 0.8 & 27.9 & 182 & 0.8 & 27.9 \\
\hline (E) T outdated blood & 0.0 & 14.7 & 182 & 0.64 & 26.2 \\
\hline (F) $T$ rejuvenated blood & 2.0 & 37.4 & 182 & 1.04 & 30.0 \\
\hline
\end{tabular}

$\mathrm{P}_{\mathrm{CO}_{2}}=40$ Torr $(5.32 \mathrm{kPa})$, and $\mathrm{pH} 7.4$, unless otherwise stated. Total $\dot{\mathrm{V}}_{\mathrm{O}_{2}}$ and $\mathrm{R}$ are set to 0.25 and $0.8 \mathrm{~L} / \mathrm{min}$, respectively. The $\mathrm{P}_{50}$ and $\mathrm{Sa}_{\mathrm{O}_{2}}$ are calculated from the reported equations (Winslow et al., 1983) at the appropriate [DPG]/[Hb], $\mathrm{P}_{\mathrm{CO}_{2}}, \mathrm{pH}$, and $\mathrm{Pa}_{\mathrm{O}_{2}}$.

\section{Results}

Table 2 shows $\dot{\mathrm{V}}_{\mathrm{O}_{2}}, \dot{\mathrm{Q}}$, and the arterio-venous oxygen difference for the organs considered (Folkow and Neil, 1971), assuming a resting subject with $\dot{\mathrm{V}}_{\mathrm{O}_{2}}=0.25 \mathrm{~L} / \mathrm{min}$,

\section{TABLE 2}

The organs and the assumed $\dot{\mathrm{V}}_{\mathrm{O}_{2}}, \dot{\mathrm{Q}}$, and arterio-venous oxygen difference (Folkow and Neil, 1971). The $\mathrm{Pv}_{\mathrm{O}_{2}}$ is either calculated from these data (assume a resting male subject with $\dot{\mathrm{V}}_{\mathrm{O}_{2}}=0.25 \mathrm{~L} / \mathrm{min}$, the control case $\mathrm{A}$, and $\mathrm{Pa}_{\mathrm{O}_{2}}=95$ Torr, $12.63 \mathrm{kPa}$ ), or predicted by the model. The slope of the curves at the corresponding $\dot{Q}$ is also reported. The oxygen consumed by these organs, and the blood flow through them account for $57 \%$ and $55 \%$, respectively, of the total requirements.

\begin{tabular}{|c|c|c|c|c|c|c|}
\hline \multirow[t]{2}{*}{ Organ } & \multirow{2}{*}{$\begin{array}{l}\dot{\mathrm{V}}_{\mathrm{O}_{2}} \\
(\mathrm{~L} / \min )\end{array}$} & \multirow{2}{*}{$\begin{array}{l}\dot{\mathrm{Q}} \\
(\mathrm{L} / \mathrm{min})\end{array}$} & \multirow{2}{*}{$\begin{array}{l}{\left[\mathrm{O}_{2}\right] \mathrm{a}-\mathrm{v}} \\
(\mathrm{ml} / \mathrm{L})\end{array}$} & \multicolumn{2}{|c|}{$\mathrm{Pv}_{\mathrm{O}_{2}}$ (Torr) } & \multirow[t]{2}{*}{$\mathrm{dP}_{\mathrm{O}_{2}} / \mathrm{d} \dot{\mathrm{Q}}$} \\
\hline & & & & calc. & model & \\
\hline Brain & 0.045 & 0.75 & 60 & 37 & 38 & 24.4 \\
\hline Heart & 0.025 & 0.25 & 100 & 27 & 29 & 83.3 \\
\hline Kidneys & 0.015 & 1.20 & 13 & 65 & 66 & 14.1 \\
\hline Legs & 0.058 & 0.80 & 70 & 34 & 35 & 22.7 \\
\hline Total & 0.250 & 5.50 & 50 & 41 & 43 & 3.6 \\
\hline
\end{tabular}


$\dot{\mathrm{Q}}=5.5 \mathrm{~L} / \mathrm{min}$, and $\mathrm{Pa}_{\mathrm{O}_{2}}=95$ Torr $(12.63 \mathrm{kPa})$, that corresponds to $\mathrm{Sa}_{\mathrm{O}_{2}}=95.8 \%$, $96.0 \%$, and $95.2 \%$ for $[\mathrm{DPG}] /[\mathrm{Hb}]=0.8,0.64$, and $1.04 \mathrm{M} / \mathrm{M}$, respectively. Data for legs are from other sources (Jorfeldt and Wahren, 1971) with the same assumptions. The $\mathrm{Pv}_{\mathrm{O}_{2}}$ calculated from the arterio-venous oxygen difference, $\mathrm{Q}$ and $[\mathrm{Hb}]$ virtually matches that predicted by the model for the control case A for all the organs (table 2, column 5 vs column 6). The last column in table 2 reports the slope of the $\mathrm{Q} v s \mathrm{Pv}_{\mathrm{O}_{2}}$ curves $\left(\mathrm{dP}_{\mathrm{O}_{2}} / \mathrm{d} \dot{\mathrm{Q}}\right)$ at the $\dot{\mathrm{Q}}$ values reported therein. The values for $\dot{\mathrm{Q}}$ and $\mathrm{Pv}_{\mathrm{O}_{2}}$ are not employed by the model, but are used to check the output of the program and to define the limits of the calculation. Figure 1 shows some examples of the $\dot{\mathrm{Q}} v s \mathrm{Pv}_{\mathrm{O}_{2}}$ relationships for two organs, at $\mathrm{Pa}_{\mathrm{O}_{2}}=95$ Torr $(12.63 \mathrm{kPa})$ and case $\mathrm{A}$.

Moderate alterations of the acid-base balance in arterial blood are simulated by varying $\mathrm{BE}$ in the -3 to $+3 \mathrm{mEq}$ range (fig. 2, left). The movements of $\mathrm{H}^{+}$in or out the blood stream across the organ are simulated setting venous $\mathrm{BE}$ to a value different from that of arterial BE (fig. 2, center). Finally, chronic lung obstruction diseases and the oxygen therapy are simulated setting $\mathrm{Pa}_{\mathrm{O}_{2}}$ to 60 and 300 Torr (7.98 and $39.9 \mathrm{kPa}$ ) respectively (fig. 2 , right).

Figure 3 shows the separate and the combined effects of [DPG]/[Hb] and of [Hb] (see table 1) on the blood flow required to maintain a predefined metabolic level in the organs, at $\mathrm{Pa}_{\mathrm{O}_{2}}=95$ Torr $(12.63 \mathrm{kPa}), \mathrm{BE}=0 \mathrm{mEq}$, and no $\mathrm{BE}$ gradient across the organ. Data shown in fig. 3 are virtually constant at any $\mathrm{Pa}_{\mathrm{O}_{2}}, \mathrm{BE}$, and $\mathrm{BE}$ gradient in the considered ranges (not shown).
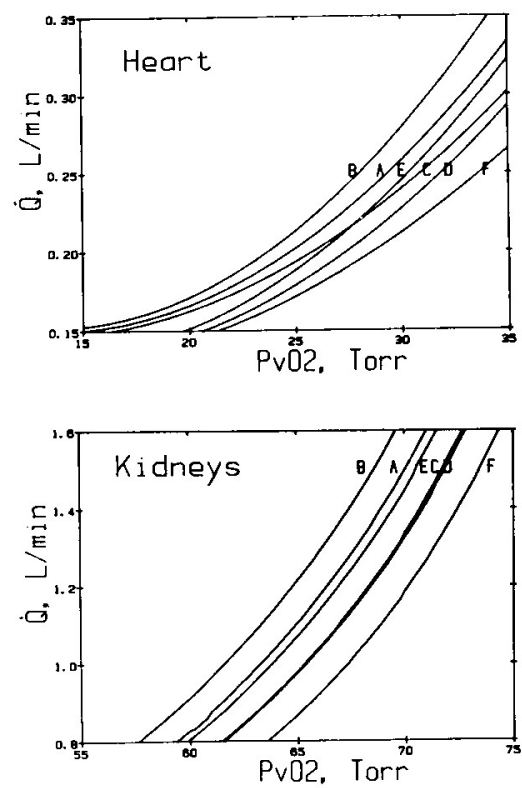

Fig. 1. $\mathrm{Pv}_{\mathrm{O}_{2}} v \dot{\mathrm{Q}}$ plots for two organs at $\mathrm{Pa}_{\mathrm{O}_{2}}=95$ Torr $(12.63 \mathrm{kPa}), \mathrm{BE}=0 \mathrm{mEq}$, and no $\mathrm{BE}$ gradient across the organ. The letters represent the cases considered in table 1. 

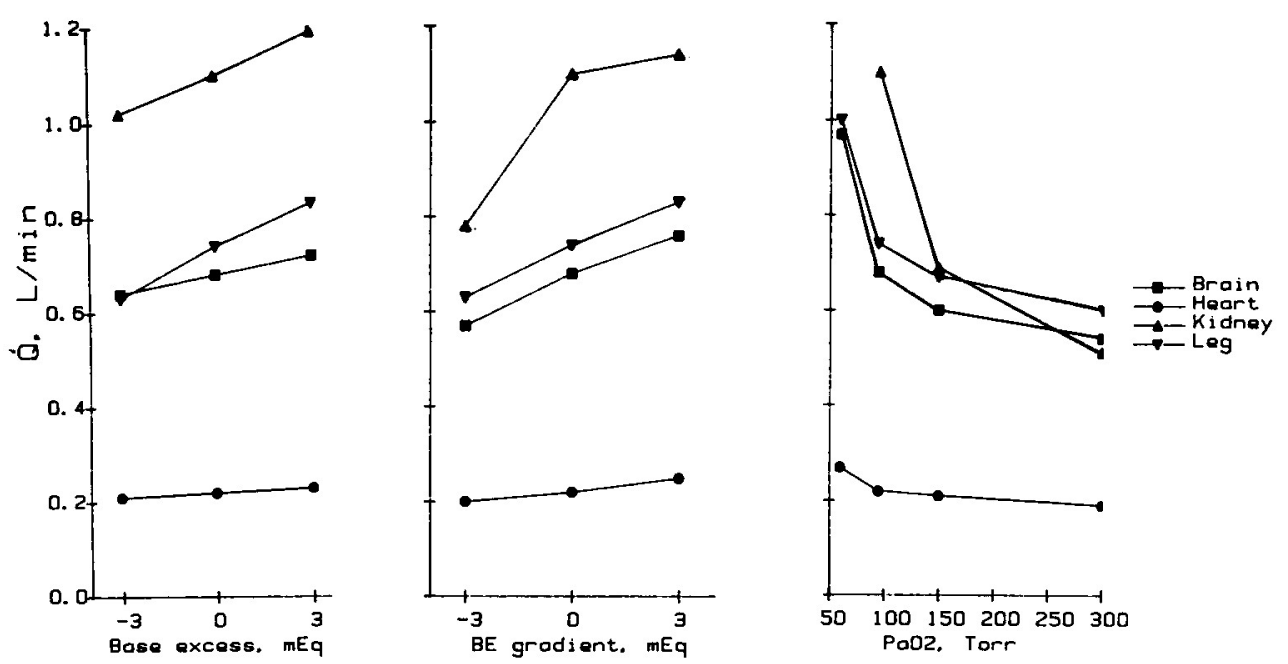

Fig. 2. Effect of a variation of arterial $\mathrm{BE}$ (left), $\mathrm{BE}$ gradient (center), and $\mathrm{Pa}_{\mathrm{O}_{2}}$ (right) on $\dot{\mathrm{Q}}$.

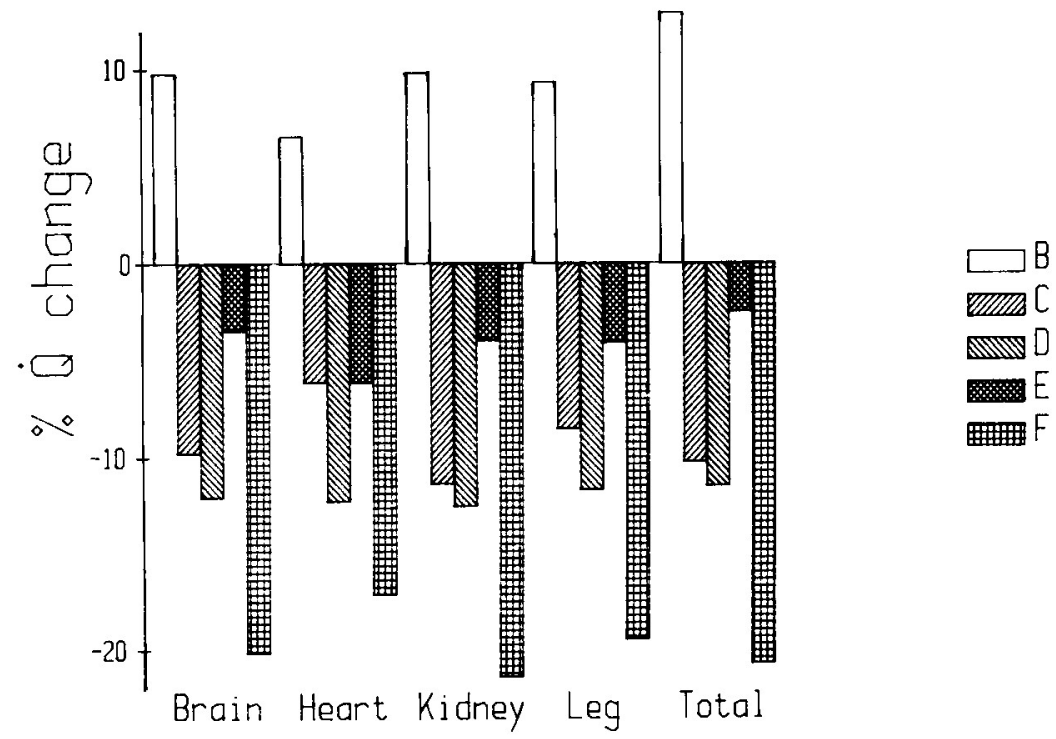

Fig. 3. Percent change of $\dot{Q}$ (with respect to case $\mathrm{A}$ ) required to maintain the predetermined metabolic level in the various organs, at $\mathrm{Pa}_{\mathrm{O}_{2}}=95 \mathrm{Torr}(12.63 \mathrm{kPa}), \mathrm{BE}=0 \mathrm{mEq}$, and no $\mathrm{BE}$ gradient across the organ. Refer to table 1 for the description of the cases. 


\section{Discussion}

As already pointed out (Samaja et al., 1986), the model employed in this study is based on the following assumptions: (1) validity of the procedure to calculate the OEC; (2) correct assessment of the acid-base balance in arterial blood and across the organ; (3) constant temperature at $37^{\circ} \mathrm{C}$ and no temperature gradients across the organ; (4) constant rheological properties of the blood in the various organs.

As previously observed (Samaja et al., 1986), the OEC calculated with the described procedure (Winslow et al., 1983) is accurate also for relevant shifts (up to 8 Torr, $1.06 \mathrm{kPa}$ ), thus the small shifts of the OEC considered in this study are likely to be correct. On the contrary, the interaction of temperature with $[\mathrm{DPG}] /[\mathrm{Hb}], \mathrm{pH}$ and $\mathrm{P}_{\mathrm{CO}_{2}}$ to affect the Adair constants and the shape of the OEC is largely unknown, thus the evaluation of the oxygen delivery in organs at temperatures different from $37^{\circ} \mathrm{C}$ is inaccurate and was not attempted in this study. However, the absence of temperature gradients across the organ seems a reasonable assumption. The effect of acid-base balance changes, as well as of BE gradients across the organ, is shown in fig. 2, left and center. The $\mathrm{pH}$ changes across the organ that are driven by the Bohr effect are routinely considered in the model (see the flowchart in the previous paper).

The model is not able at present to include the rheological factors, but the observation that the calculated $\mathrm{Pv}_{\mathrm{O}_{2}}$ virtually matches that predicted by the model for the control case A supports, although it is not a proof, that this model is an appropriate description of the oxygenation of the organs with blood of varying composition.

The oxygenation of the organs is a complex function of blood supply, metabolic level of the organ, $\mathrm{O}_{2}$ carrying characteristics of the red cells, and $\mathrm{Ca}_{\mathrm{O}_{2}}$. Nevertheless, the dependency of a given organ on $\dot{Q}$ is conveniently expressed as the slope of the $\mathrm{Pv}_{\mathrm{O}_{2}}$ $v s . \dot{Q}$ curves at the most probable $\dot{Q}$ value reported in table 2 . High values for the slope indicate that the oxygenation of the organ is more critically dependent on $\dot{Q}$ than on $\mathrm{Pv}_{\mathrm{O}_{2}}$. Consequently, a small shift of the OEC is more critical for the heart and the brain rather than for the kidneys, thus providing a theoretical support for observed data (Woodson and Auerbach, 1982).

An increase of [DPG]/[Hb] from 0.8 to $1.04 \mathrm{M} / \mathrm{M}$ appears always advantageous in terms of the blood pumping cost, regardless of the organ, the $\mathrm{Pa}_{\mathrm{O}_{2}}$, the $\mathrm{BE}$, and the $\mathrm{BE}$ gradient in the considered ranges. This advantage is different in the various organs, and is roughly equivalent to a $[\mathrm{Hb}$ ] increase from 160 to $182 \mathrm{~g} / \mathrm{L}$ (compare cases $\mathrm{C}$ and $\mathrm{D}$ in fig. 3), but without the corresponding increase of the blood viscosity and the vascular resistance. However, since the rheological factors were not considered in the model, it is likely that cases D, E, F are less advantageous than described in fig. 3 .

In conclusion, while the previous study (Samaja et al., 1986) showed that whole body metabolism at rest and during exercise can be described in terms of the blood flow and the blood oxygen carrying characteristics both at sea level and at altitude, this study shows that this model can be adapted to the organ metabolism as well. The dependency of the metabolic level on blood perfusion is evaluated in terms of the $\mathrm{dP}_{\mathrm{O}_{2}} / \mathrm{dQ}$ ratio. The higher this ratio, the more critically dependent on the blood flow is the organ. 
Finally, the advantages of transfusing blood with high [DPG]/[Hb] are quantitatively assessed in terms of the economy of the blood perfusion. It can thus be concluded that this model is a useful tool for the quantitative evaluation of the efficiency of the oxygen transport system at the organ, as well as at the whole body level.

Acknowledgements. The great help kindly provided by Prof. P. E. diPrampero in discussing the results reported in this work is gratefully acknowledged. This work was supported by grant no. 86.00139 from the Consiglio Nazionale delle Ricerche, Roma.

\section{References}

Folkow, B. and E. Neil (1971). Circulation. New York, Oxford University Press.

Jorfeldt, L. and J. Wahren (1971). Leg blood flow during exercise in man. Clin. Sci. 41: 459-473.

Samaja, M., P.E. diPrampero and P. Cerretelli (1986). The role of 2,3- DPG in the oxygen transport at altitude. Respir. Physiol. 64: 191-202.

Valeri, C.R. (1976). Blood Banking and the Use of Frozen Blood Products. Cleveland, OH, CRC Press.

Winslow, R.M., M. Samaja, N.J. Winslow, L. Rossi-Bernardi and R.I. Shrager (1983). Simulation of continuous blood $\mathrm{O}_{2}$ equilibrium curve over physiological pH, DPG, and $\mathrm{P}_{\mathrm{CO}_{2}}$ range. J. Appl. Physiol. 54: 524-529.

Woodson, R. D. and S. Auerbach (1982). Effect of increased oxygen affinity and anemia on cardiac output and its distribution. J. Appl. Physiol. 53: 1299-1306. 